\title{
The impact of obesity on left ventricular mass and left ventricular systolic function in children
}

\author{
Ria Nova, MD; Bambang Madiyono, MD; Sudigdo Sastroasmoro, MD, PhD; \\ Damayanti R Sjarif, MD, PhD
}

\begin{abstract}
Background Obesity causes cardiovascular disturbances. The incidence of cardiovascular disease is higher even in mildly obese patients than in lean subjects.

Objectives The purpose of this study was to compare left ventricular (LV) mass, LV internal dimensions, and LV systolic function between obese and normal children; and to determine the association of the degree of obesity with LV mass and LV systolic function.

Methods This cross-sectional study was conducted on elementary school students in Jakarta from February to April 2003. We measured the subjects' body weight and height, and performed lipid profile and echocardiography examinations. Measurements of LV mass, LV internal dimensions with regard to septum thickness, LV internal diameter, and LV posterior wall thickness; and LV systolic function as indicated by shortening fraction and ejection fraction, were performed echocardiographically. The differences in measurements between obese and normal children as well as between obese children with and without lipid abnormality were analyzed. The correlation between the degree of obesity with LV size and systolic function was determined.

Results Twenty-eight normal children and 62 obese children were enrolled in the study. Mean LV mass was 35.7 (SD 5.16) g/ $/ \mathrm{cm}^{3}$ in obese children versus 24.0 (SD 3.80) $\mathrm{g} / \mathrm{cm}^{3}$ in normal children $(P<0.0001)$. Mean septum thickness was $0.8(S D 0.14) \mathrm{mm}$ in obese children versus 0.6 (SD 7.90) $\mathrm{mm}$ in normal children $(\mathrm{P}<$ 0.0001 ). Mean posterior wall thickness was 0.9 (SD 0.14) $\mathrm{mm}$ in obese children versus 0.6 (SD 9.97) $\mathrm{mm}$ in normal children $(P<0.0001)$. Mean LV internal diameter was 4.0 (SD 0.34) $\mathrm{mm}$ in obese children versus 3.9 (SD 0.29) $\mathrm{mm}$ in normal children $(P=0.300)$. There was strong correlation between the degree of obesity and LV mass $(r=0.838, P<0.0001)$. LV systolic function (shortening fraction) was 37.1 (SD 4.20) percent in obese children versus 35.8 (SD 4.99) percent in normal children ( $P=0.19)$. Ejection fraction was 67.4 (SD 5.32) percent in obese children versus 65.5 (SD 6.29) percent in normal children $(P=0.13)$. There was weak correlation between LV systolic function and the degree of obesity (shortening fraction $\mathrm{r}=0.219, \mathrm{P}=0.038$; ejection fraction $\mathrm{r}=0.239, \mathrm{P}=0.023$ ).

Conclusions Obese children had significantly greater LV mass, septum thickness, and posterior wall thickness than normal chil-
\end{abstract}

dren. Such significant difference was absent for LV internal diameter and measures of LV systolic function. There was no significant difference in LV mass and LV systolic function between obese children with or without abnormality of lipid profile. A strong correlation exists between the degree of obesity and LV mass, but the correlation between degree of obesity and LV systolic function was weak [Paediatr Indones 2005;45:171-176].

Keywords: childhood obesity, left ventricular mass, left ventricular systolic function

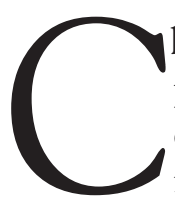

hildhood obesity is a major public health problem and evidence shows that this will continue onto adulthood. Obesity results in systemic abnormalities which may cause morbidity and mortality. The incidence of cardiovascular disturbance is higher in even mildly obese patients than in normal subjects. Cardiovascular complications of obesity include hypertension, dyslipidemia, insulin resistance, glucose intolerance, and type II diabetes mellitus, which may accelerate the development of vascular diseases, left ventricular hypertrophy, and pulmonary hypertension due to obstructive sleep apnea. ${ }^{1-3}$

From the Department of Child Health, Medical School, University of Indonesia, Jakarta, Indonesia.

Reprint requests to: Ria Nova, MD, Department of Child Health, Medical School, University of Indonesia, Cipto Mangunkusumo Hospital, Jl. Salemba No. 6, Jakarta 10430, Indonesia. Tel. 62-21-3907742; Fax. 62 21-3907743; Email: rialuthfan@yahoo.com. 
It is well-known that long-standing obesity is associated with left ventricular dilatation and impaired systolic function in adults. ${ }^{4-8}$ However, there is little information concerning its impact on left ventricular mass and left ventricular systolic function in obese children. As of yet, there is no report of this in Indonesia. This study aimed to compare left ventricular (LV) mass, LV internal dimensions, and LV systolic function between obese and normal children; and to determine the association of the degree of obesity with LV mass and LV systolic function.

\section{Methods}

This cross-sectional study was conducted at Al Azhar Elementary School, Rawamangun, East Jakarta from January to March 2003. The subjects of the study were fourth-through sixth-grade obese and normal-weight primary school students. The subjects were selected by simple random sampling.

Subjects' personal data were collected by filling questionnaires. Measurements of body weight and height were performed by using two scales (Detecto Medic). Serum levels of total cholesterol, high-density lipoprotein (HDL) cholesterol, low-density lipoprotein (LDL) cholesterol, triglyceride (TG), and apoprotein-B (Apo-B) were determined. Measurement of LV internal dimensions, LV mass and LV systolic function were performed by echocardiography using Agilent Sonos 4500.

The obesity criteria used was based on body mass index (BMI) for age. BMI for age above the $95^{\text {th }}$ percentile on the Centers for Disease Control (CDC) growth charts was classified as obesity. LV mass and
LV systolic function were assessed using M-mode echocardiography. We compared data of obese and normal children as well as of obese children with and without lipid profile abnormality. We also analyzed the correlation of the degree of obesity with LV mass and LV systolic function. LV internal dimensions measured were septum thickness, LV internal diameter, and LV posterior wall thickness. The indicators used to assess LV systolic function were shortening fraction (SF) and ejection fraction $(\mathrm{EF})$.

Data were tabulated and analyzed using SPSS 11 version. The difference between quantitative data was analyzed using the t-test. Statistical significance was set at $\mathrm{P}<0.05$. Correlation of the degree of obesity with LV mass and LV systolic function were assessed using Pearson's correlation analysis.

Ethical approval for this study was given by the Medical Research Ethics Committee of the Medical School, University of Indonesia.

\section{Results}

Three hundred and sixty students, consisting of 177 boys (49\%) and 183 girls (51\%), underwent body

Table 1. Characteristics of study subjects

\begin{tabular}{lrl}
\hline Characteristic & $\mathbf{n}$ & $\%$ \\
\hline Sex & & \\
Male & 177 & 49 \\
Female & 183 & 51 \\
Nutritional status & & \\
Underweight & 86 & 24 \\
Normal & 54 & 15 \\
Overweight & 109 & 30 \\
Obese & 111 & 31 \\
\hline
\end{tabular}

TABle 2. Comparison of LV MASS, LV INTERNAL DIMENSIONS, AND LV SYSTOLIC FUNCTION BETWEEN OBESE AND NORMAL SUBJECTS

\begin{tabular}{|c|c|c|c|}
\hline \multirow[t]{2}{*}{ Variable } & \multicolumn{2}{|c|}{ Mean value } & \multirow[t]{2}{*}{$\mathbf{P}^{*}$} \\
\hline & Obese & Normal-weight & \\
\hline \multicolumn{4}{|l|}{ LV internal dimensions } \\
\hline Septum thickness (mm) & 0.8 (SD 0.14) & 0.6 (SD 7.9) & $P<0.0001$ \\
\hline LV diameter $(\mathrm{mm})$ & 4.0 (SD 0.34) & 3.9 (SD 0.29) & $P=0.300$ \\
\hline LV posterior wall thickness (mm) & 0.9 (SD 0.18) & 0.6 ( SD 9.97) & $P<0.0001$ \\
\hline LV mass $\left(\mathrm{g} / \mathrm{cm}^{3}\right)$ & 35.7 (SD 5.16) & 24.0 (SD 3.80) & $P<0.0001$ \\
\hline \multicolumn{4}{|l|}{ LV systolic function } \\
\hline EF (\%) & 67.4 (SD 5.32) & 65.5 (SD6.29) & $P=0.13$ \\
\hline FS (\%) & 37.1 (SD 4.20) & 35.8 (SD 4.99) & $P=0.19$ \\
\hline
\end{tabular}

* $\mathrm{t}$-test for 2 independent groups 
Ria Nova et al: The impact of obesity on left ventricular mass and systolic function

Table 3. Comparison of LV mass between obese ChildRen With NORMAL AND ABNORMAL LIPID PROFILE

\begin{tabular}{|c|c|c|c|}
\hline Lipid profile & $\mathbf{n}$ & LV mass $\left(\mathrm{g} / \mathrm{cm}^{3}\right)$ & $\mathbf{P}$ \\
\hline \multicolumn{4}{|l|}{$\mathrm{LDL}(\mathrm{mg} / \mathrm{dl})$} \\
\hline$<130$ & 44 & 35.5 (SD 5.51) & $P=0.640$ \\
\hline$\geq 130$ & 18 & 36.2 (SD 5.07) & \\
\hline \multicolumn{4}{|c|}{ Triglyceride (mg/dl) } \\
\hline$<200$ & 56 & 35.8 (SD 5.05) & $P=0.866$ \\
\hline$\geq 200$ & 6 & 35.4 (SD 6.72) & \\
\hline \multicolumn{4}{|l|}{ Apo-B (mg/dl) } \\
\hline$<109$ & 57 & 35.7 (SD 4.98) & $P=0.942$ \\
\hline$\geq 109$ & 5 & 35.9 (SD 7.73) & \\
\hline
\end{tabular}

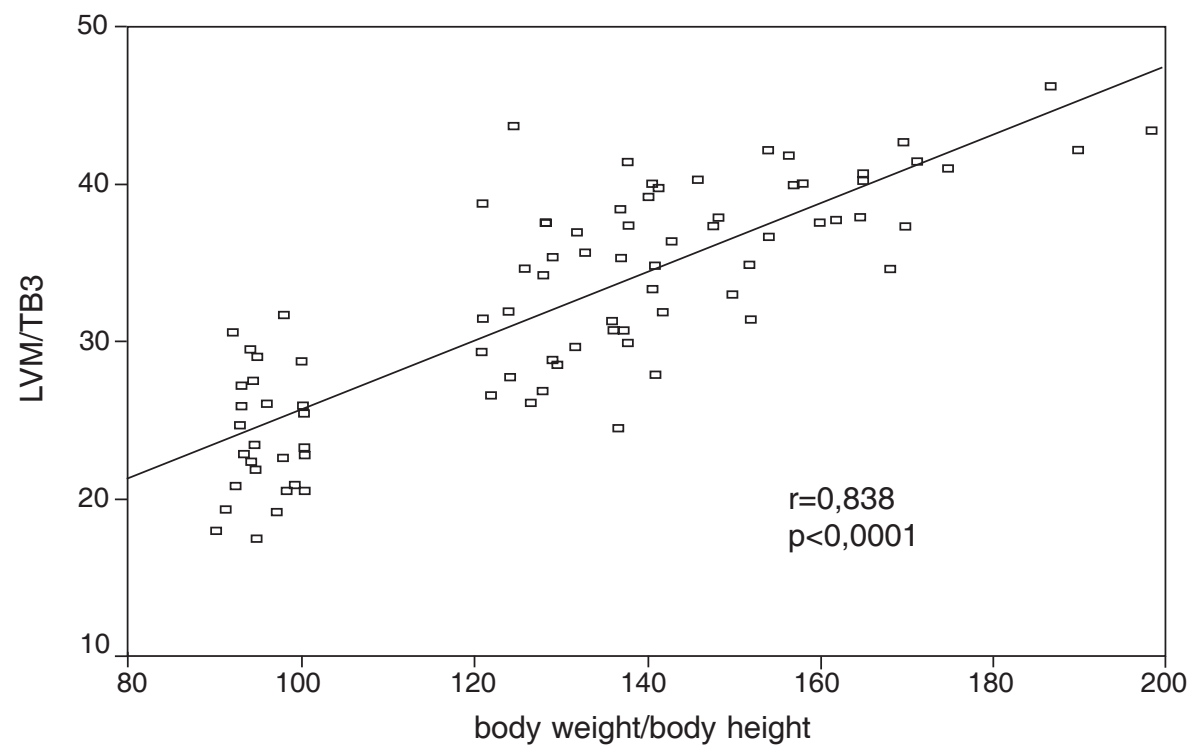

Figure 1. Correlation betWeEn LV MASS AND BOdY WEIGHT PER BODY HeIGHT

weight and height measurements. Eighty-six children (24\%) were underweight, 54 (15\%) had normal weight; 109 (30\%) were overweight, and 111 (31\%) were obese (Table 1). Out of 111 children with obesity and 54 children with normal weight, 90 consented to full check-up, consisting of 62 with obesity and 28 with normal weight.

LV mass was compared between obese and normal-weight children. The average LV mass was 35.7 (SD 5.16) $\mathrm{g} / \mathrm{cm}^{3}$ in obese children and 24.0 (SD 3.80) $\mathrm{g} / \mathrm{cm}^{3}$ in normal children $(\mathrm{P}<0.0001)$. The difference in mean LV mass between obese and normal-weight children was statistically significant. Septum thickness and LV posterior wall thickness were also significantly greater in obese children than in normal ones. How- ever, LV internal diameter and LV systolic function was not significantly difference between obese and normal-weight children (Table 2). Shortening fraction (SF) was 35.8\% (SD 4.99\%) in obese children and $37.1 \%(\mathrm{SD} 4.20 \%)$ in normal children $(\mathrm{P}=0.19)$. Ejection fraction (EF) was 65.5\% (SD 6.29\%) in obese children and $67.4 \%$ (SD 5.32\%) in normal children $(\mathrm{P}=0.13)$.

Half of the obese children had abnormal lipid profile, but it did not seem to influence LV mass. LV mass was not significantly different between obese children with and without abnormal lipid profile (Table 3).

Figure 1 shows the correlation between the degree of obesity and LV mass. There was a strong, sta- 


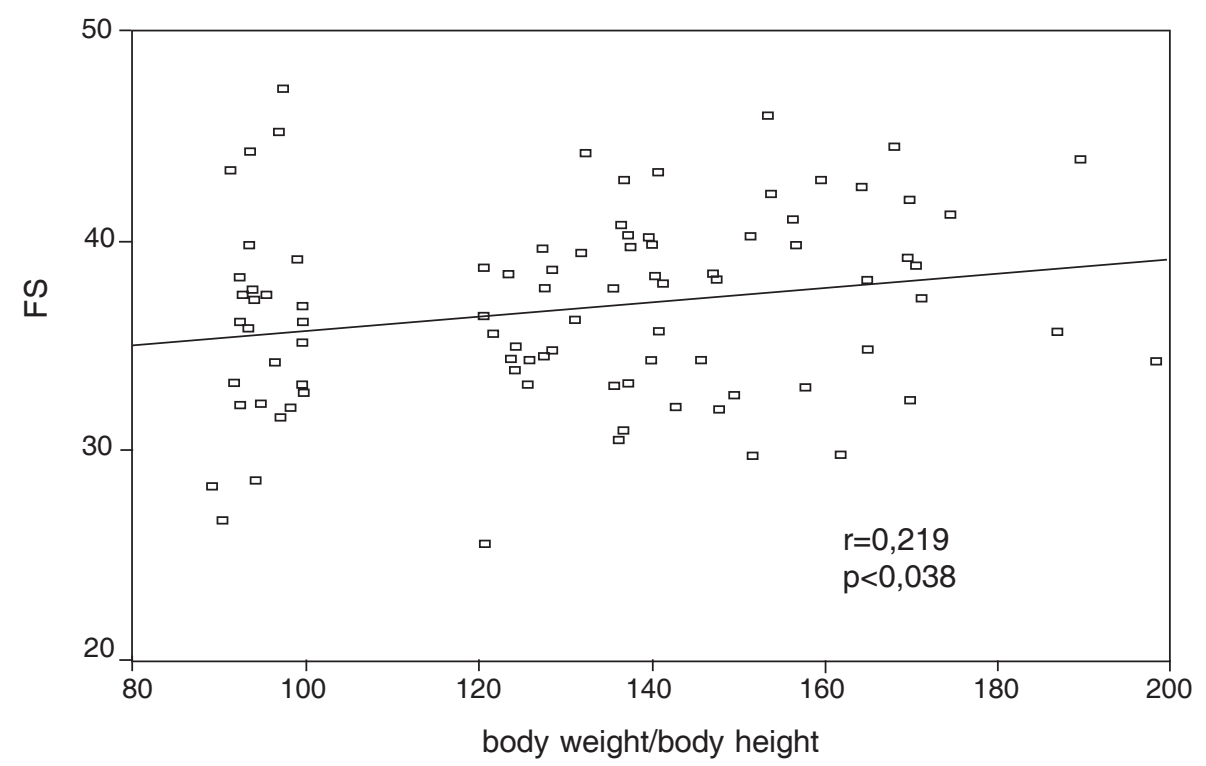

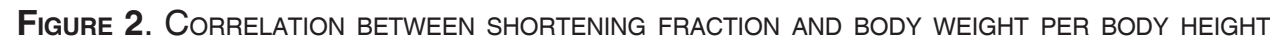

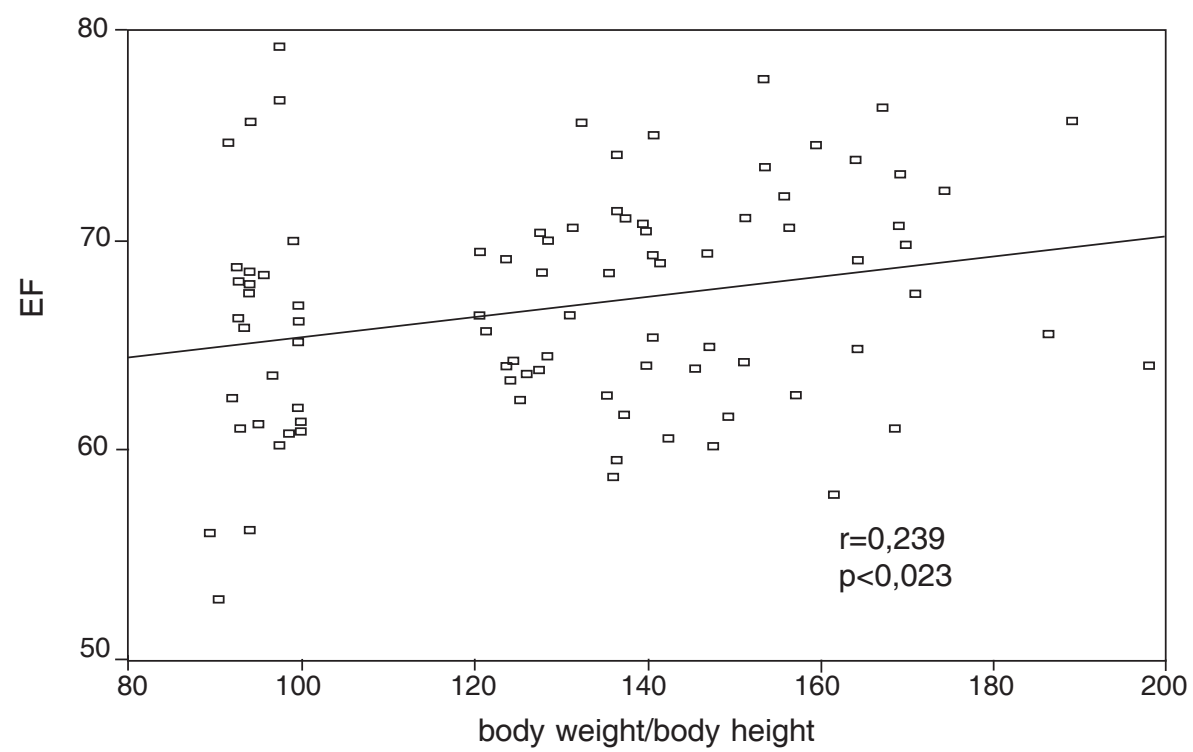

Figure 3. Correlation between ejection fraction and body Weight per body height

tistically significant correlation between the degree of obesity as denoted by body weight per body height and greater LV mass $(\mathrm{r}=0.838, \mathrm{p}<0.0001)$.

Figures 2 and 3 show the correlation of the degree of obesity with LV systolic function as indicated by shortening fraction and ejection fraction, respectively. There was weak correlation between the degree of obesity and lower LV systolic function $(\mathrm{r}=0.219, \mathrm{P}=0.038$ for $\mathrm{SF}$ and $\mathrm{r}=0.239, \mathrm{P}=0.023$ for $\mathrm{EF})$.

\section{Discussion}

The aberration in LV mass and structure are of great importance. Left ventricular hypertrophy is one of the strongest risk factors for cardiovascular morbidity and mortality. Moreover, an increase in relative wall thickness has been shown to enhance cardiovascular risks. The changes in LV mass and structure with increasing body weight can be partially explained by the hemodynamic changes that accompany obesity. As 
body weight increases, total blood volume and cardiac output rise, thus leading to a volume overload which causes left ventricular dilatation and a parallel thickening of the ventricular wall (eccentric left ventricular hypertrophy). Karason et $a l^{5}$ reported that LV mass of obese adults (37-61 years old) was greater than that of normal adults. There was a significant decrease in LV mass, septum thickness, and LV posterior wall thickness after one year of intervention. Kano et $a l^{9}$ reported that obesity has influence towards LV structure at an age as early as six years. According to Mitchell et $a l,{ }^{6}$ the increase in LV mass can be detected in an earlier stadium of obesity. In our study we compared LV mass, interventricular septum thickness, LV posterior wall thickness, LV internal diameter, and LV systolic function (shortening fraction and ejection fraction) between 62 obese children and 28 normalweight children. In accordance with results of previous studies, our data showed that LV mass in obese children was greater than that of normal children, and that interventricular septum and LV posterior wall thickness in obese children was also greater than those of normal children. In this study the youngest subject was 9 years old. This study showed that there was strong correlation between the degree of obesity and LV mass $(r=0.838$, $\mathrm{P}<0.0001$ ). Similarly, studies by Alpert et $a l^{8}$ and DeSimone et al ${ }^{10}$ reported strong correlation between LV mass and abnormal lipid profile in obese children and adults. Marricone et $\mathrm{al}^{4}$ reported that in obese adults, $\mathrm{LV}$ internal diameter was significantly larger than in normal subjects $(\mathrm{P}=0.001)$. Alpert et $\mathrm{al}^{7}$ found strong correlation between the length of obesity period and the increase in $\mathrm{LV}$ internal diameter $(\mathrm{r}=0.71)$. On the contrary, in this study there was no difference in LV internal diameter between obese and normal children.

There was no significant difference in LV systolic function between obese and normal children. In obese children, only LV hypertrophy was found; dilatation has not yet occured, which might explain why the LV systolic function was within normal limits. Our study showed that there was weak correlation between the degree of obesity and decreased LV systolic function, as did that of Nakajima et al. ${ }^{11}$ Contrastingly, Alpert et $\mathrm{al}^{7}$ reported that decreased LV systolic function and obesity were correlated.

We conclude that LV mass in obese children was greater than that in normal-weight children. However, LV systolic function in obese children was still within normal limits. There was strong correlation between the degree of obesity with LV mass. LV mass in obese children increased even with normal lipid profile was still normal. Therefore, it is important to evaluate cardiac morphology and function in obese children even if they have no cardiac symptoms. Further study is needed to understand the influence of the duration of obesity towards left ventricle function, particularly with regard to systolic time interval and diastolic function.

\section{References}

1. Jousilahti P, Tuomilehto J, Vartiainen E, Pekkanen J, Puska P. Body weight, cardiovascular risk factors and coronary mortality. Fifteen year follow up of middle aged men and women in eastern Finland. Circulation 1996;93:1372-9.

2. Calle EE, Thun MJ, Petrelli JM, Rodriguez C, Heath $\mathrm{CW}$. Body mass index and mortality in a prospective cohort of U.S adults. N Engl J Med 1999;341:1097105.

3. Sheehan MT, Jensen MD. Metabolic complication of obesity. Pathophysiologic considerations. Med Clin North Am 2000; 84:363-79.

4. Morricone L, Malavazos AE, Coman C, Donati C, Hassan J, Caviezel F. Echocardiographic abnormalities in normotensive obese patients: relationship with visceral fat. Obesity Research 2002;10:489-98.

5. Karason K, Wallentin I, Larsson B, Sjostrom L. Effects of obesity and weight: loss on left ventricular mass and relative wall thickness: survey and intervention study. BMJ 1997; 315:912-6.

6. Mitchell BM, Gutin B, Kapuku G, Barbeau P, Humphries MC, Owen S, et al. Left ventricular structure and function in obese adolescent: relations to cardiovascular fitness, percent body fat and visceral adiposity and effects of physical training. Pediatrics 2002; 109:1-11.

7. Alpert MA, Lambert CR, Panayiotou H, Terry BE, Cohen MV, Massey CV, et al. Relation of duration of morbid obesity to left ventricular mass, systolic function and diastolic filling and effect of weight loss. Am J Cardiol 1995; 76:1194-7.

8. Alpert MA, Terry BE, Lambert CR, Kelly DL, Panayiotou H, Mukerji V, et al. Factors influencing left ventricular systolic function in nonhypertensive mor- 


\section{Paediatrica Indonesiana}

bidly obese patients and effect of weight loss induced by gastroplasty. Am J Cardiol 1993; 71:733-7.

9. Kono Y, Yoshinaga M, Oku S, Nomura Y, Nakamura M, Aihoshi S. Effect of obesity on echocardiographic parameters in children. Int J Cardiol 1994; 46:7-13.

10. DeSimone G, Daniles SR, Devereux RB, meyer RA, Roman MJ, Divitiis O, et al. Left ventricular mass and body size in normotensive children and adults: assessment of allometric relations and impact of overweight. J Am Coll Cardiol 1992; 20:1251-60.

11. Nakajima T, Fujioka S, Tokunaga K, Hirobe K, Matsuzawa Y, Tarui S. Noninvasive study of left ventricular performance in obese patients: influence of duration of obesity. Circulation 1985; 71:481-6. 